OPEN ACCESS

Edited by:

Shaljan Areepattamannil, Emirates College for Advanced Education, United Arab Emirates

Reviewed by:

Rubén López-Bueno,

National Research Centre for the Working Environment,

Denmark

Michael Melkonian,

Emirates College for Advanced Education, United Arab Emirates

*Correspondence: Wei Zeng

weizengscnu@foxmail.com

Specialty section:

This article was submitted to Educational Psychology, a section of the journa

Frontiers in Psychology

Received: 09 February 2021 Accepted: 12 April 2021

Published: 06 May 2021

Citation:

Xu Y, Shao J, Zeng W, Wu X, Huang D, Zeng $Y$ and Wu J (2021)

Depression and Creativity During

COVID-19: Psychological Resilience as a Mediator and Deliberate

Rumination as a Moderator.

Front. Psychol. 12:665961. doi: 10.3389/fpsyg.2021.665961

\section{Depression and Creativity During COVID-19: Psychological Resilience as a Mediator and Deliberate Rumination as a Moderator}

\author{
Yanhua $X u^{1}$, Jinlian Shao ${ }^{2}$, Wei Zeng ${ }^{2 *}$, Xingrou $W^{2}$, Dongtao Huang ${ }^{2}$, Yuqing Zeng ${ }^{2}$ \\ and Jiamin $W u^{2}$ \\ ${ }^{1}$ College of Resource Environment and Tourism, Capital Normal University, Beijing, China, ${ }^{2}$ School of Geography, South \\ China Normal University, Guangzhou, China
}

Purpose: The pandemic of coronavirus disease 2019 (COVID-19), which has had a significant impact on people's lives, has apparently increased the incidence of depression. Although the topic of how depression affects creativity is contested, previous research has revealed a significant relationship between the two. The purpose of this study is to further investigate the relationship and the mechanisms that operate between depression and creativity.

Methods: A total of 881 students at an independent college in China completed a questionnaire consisting of the Self-Reported Depression Scale, Runco Ideational Behavior Scale, Psychological Resilience Scale, Deliberate Rumination Scale and demographic information. Among the respondents, 317 (36.0\%) were male and 564 (64.0\%) were female, all of whom were from the same grade. Correlation analyses were conducted, and then the researchers carried out mediation analysis and developed a moderated mediation model.

Results: The results indicated that (a) depression was positively related to creativity $(r=0.085, p<0.05)$; (b) psychological resilience mediated the relationship between depression and creativity; specifically, psychological resilience was negatively related to depression $(r=-0.462, p<0.01)$, which in turn was positively related to creativity $(r=0.198, p<0.01)$; and (c) deliberate rumination moderated the relationship between depression and psychological resilience, showing a significant negative correlation with depression $(r=0.138, p<0.01)$, psychological resilience $(r=0.078, p<0.05)$, and creativity $(r=0.288, p<0.05)$; specifically, higher levels of deliberate rumination strengthened the negative correlation between psychological resilience and depression.

Conclusion: The results suggest that depression is a positive predictor of creativity and may promote creativity to some extent. Further, individuals with greater psychological resilience are more creative than those with less psychological resilience, as it is a question of whether they can and to what extent they can effectively use depression 
as an emotional resource. Last, an individual's level of deliberate rumination moderates the mediating process, especially at the stage where depression is associated with psychological resilience. These findings advance understanding of the mechanisms that operate between depression and creativity.

Keywords: depression, creativity, psychological resilience, deliberate rumination, moderated mediation model, college students

\section{INTRODUCTION}

The coronavirus disease 2019 (COVID-19) has had an increasing impact on humans. According to the World Health Organization, COVID-19 may persist for a long time. As the pandemic has worsened, governments have locked downed cities and decreed social-isolation measures for residents (Zhou et al., 2020), which has increased the risk of people developing psychological disorders. A survey of 1,770 Chinese citizens showed a $47.1 \%$ prevalence of depression and an $18.2 \%$ prevalence of major depressive symptoms due to social isolation and other reasons (Ran et al., 2020). Similarly, a longitudinal investigation showed that the stress of the pandemic has had a significant impact on the college students (Wang et al., 2020), who showed varying degrees of anxiety and depression due to factors such as financial pressure and academic delays (Dhar et al., 2020). Therefore, it is important to focus on the emotional impact of the pandemic on people.

This public health emergency has triggered significant negative emotions in individuals, especially depressive symptoms. Social isolation can cause loneliness and interpersonal disconnection. Especially for those who are socially most vulnerable, feelings of exhaustion, anxiety, distress, and trauma can grow, leading to significant clinical symptoms of psychological disorders and an increased risk of depression (Pietrabissa and Simpson, 2020). Stressors such as the economic crisis, the threat of unemployment or the fear of losing a loved one can further increase the psycho-emotional risk of fatigue, depression, insomnia, and loneliness (Bartoszek et al., 2020). Also, though they respond differently depending on their developmental stage, children may experience high rates of anxiety, depression, and post-traumatic symptoms (Marques de Miranda et al., 2020). Thus, depression has been identified as a main psychological disorder emerging in individuals during the pandemic, affecting their lives and mental health.

Though depression may negatively affect individuals, its relationship with creativity has been of interest to scholars (Kim et al., 2016). Being in a negative frame of mind does not always have a negative impact on a person's motivation and creativity. It has been suggested that individuals exhibit great artistic creativity when they are physiologically susceptible to negative emotions and exposed to environments that bring about strong negative emotions (Akinola and Mendes, 2008). However, the relationship between psychopathology and creativity has long been controversial (Paek et al., 2016), and more in-depth research is needed.

Depression, as a negative emotion, is closely related to an individual's mental health and may affect an individual's psychological resilience (Poole et al., 2017; Liu et al., 2018; Xiang et al., 2018, 2020), but there has been little research on psychological resilience as a mediating pathway for the transformation of depression into creativity. Similarly, it has been shown that the relationship between negative emotions and creativity may be influenced by an individual's internal psychological environment, such as their level of rumination (Verhaeghen et al., 2005; Cohen and Ferrari, 2010). What is more, rumination has served as a mediator and moderator in studies related to negative emotions such as anxiety and depression (Liu et al., 2017). However, there is a paucity of research on how rumination is associated with depression, psychological resilience and creativity. This has prompted the authors to reflect on how depression may have affected an individual's creativity during the pandemic and whether psychological resilience and rumination played a role in this relationship.

In short, the role of psychological resilience and rumination in mediating the relationship between depression and creativity during COVID-19 has rarely been studied. Further research is warranted as it may be relevant to the mental health of individuals during the pandemic as well as to their social adjustment and creativity in the post-pandemic era.

This study explores the relationship between depression and creativity among college students during COVID-19 as well as the mediating role of Psychological Resilience and considers the inclusion of deliberate rumination as a moderator in the model. These four variables and their relationships are discussed in the following section.

\section{THEORETICAL BASIS AND HYPOTHESES}

\section{Creativity}

Creativity has been a subject of extensive and continuing discussion. Defined as the process by which people think and act to produce novel works (Guilford, 1950), creativity was said to comprise four steps: preparation, incubation, illumination, and verification (Wallas, 1926). After decades of extensive research, a deeper understanding developed of the competencies, characteristics, and cognitive processes associated with creativity (Plucker et al., 2004; Cadle, 2015), and researchers took a more nuanced and interdisciplinary approach to understanding creativity (Goswami, 1996). For example, a recent grounded-theory study proposed that the creative process for journalists goes through four stages: cognition, cultivation, capture, and reflection (Rubenstein et al., 2017). 
Some studies have taken a dynamic view, arguing that creative achievement and creative uncertainty are key to the creative process (Corazza, 2016). Some researchers have classified creativity as "big-C" or "little-c" (Gardner, 1993). Big-C creativity refers to excellence in fields such as art, science and other fields, while "little-c" creativity refers to the ability to problem-solve so as to adapt to changes in society and daily life and create new opportunities for oneself (Runco, 2004).

A wealth of research has provided a broader understanding of the meaning and process of creativity, but no one definition is universally accepted by scholars. However, it is generally accepted that creativity is a cognitive process characterized by the ability to generate novel ideas (Runco and Basadur, 1990; Varshney et al., 2013). It is closely related to intelligence (Sternberg, 2017), including to important competencies such as divergent thinking (Zhu et al., 2019), problem identification (Hah, 2006), creative problem-solving (Isen et al., 1987), and breadth of attention (Fredrickson and Branigan, 2005). Therefore, it can be inferred that creativity is influenced by a very large number of factors. According to Sternberg's triangular theory of creativity, individuals challenge the crowd, themselves and the zeitgeist in different combinations that lead to different manifestations of creativity (Sternberg, 2018). What is more, creativity behaves differently in different situations, such as in artistic creation (Xurui et al., 2018), corporate innovation (Lee et al., 2004; Ding et al., 2019), everyday emotion (Han et al., 2019), and psychopathology (Sampedro et al., 2020). But the essence of creativity can be seen as a cognitive process (Leschziner and Brett, 2019).

Much research has examined how creativity as a cognitive process is influenced by other factors, and the relationship between emotion and creativity has been of great concern. The mainstream consensus is that positive emotions promote creativity, but research on the relationship between negative emotions and creativity is somewhat contradictory. A comparative analysis found that under induced conditions negative emotions had a more obvious effect on creative problem-solving than did positive emotions (Kaufmann and Vosburg, 1997). Conversely, it has also been argued that negative emotional states take a bottom-up cognitive processing and that being overly cautious, which decreases attention span, diminishes an individual's creative expression (Miller et al., 2019; Lai et al., 2020). In the dual-path model of creativity, it is argued that being in activating mood states, whether positive or negative, enhances creativity, and it is just that positive emotions stimulate cognitive flexibility, while negative emotions stimulate persistence (De Dreu et al., 2008). Thus, a direct linear relationship between negative emotions and creativity has not been confirmed by a strong and accepted research result. Also, the relationship between different dimensions of negative emotions, especially of psychological disorders, and creativity has not been definitively established (Kim et al., 2016).

Based on the above studies, we can affirm that the nature of the correlation of negative emotions (such as anxiety, depression and suppression) and creativity is contested.

\section{Depression}

Depression, as a major factor in negative affect, is seen as one manifestation of psychological disorder (Beck et al., 2003; Cox et al., 2019). Major features of depression are considered to include diminished self-esteem and self-motivation and ineffective perception of important life goals (Lovibond and Lovibond, 1995; Antony et al., 1998). When it comes to creativity and depression, there is a saying that "there is a thin line between genius and madness," and many studies have shown a link between the two. In his studies of luminaries, Post $(1996,2018)$ found that while these famous people had great character qualities and creative ability, they also showed more frequent "neuroticism" and a higher tendency toward depression and alcoholism than the average person, especially those who were writers and visual artists. Bipolar depression has also been associated with increased creativity (Andreasen, 1987; Richards et al., 1988), and people with such a disorder are more likely to have creative occupations (Kyaga et al., 2018). Further support can be found in several meta-analyses in which mood disorders (anxiety, depression, and ADHD) and psychiatric disorders were more strongly associated with the creativity of geniuses (big-C) than with the creativity of the general population (little-c) (Acar and Sen, 2013; Paek et al., 2016). Importantly, a study in which adrenal steroids were used as a measure of depressive mood found that individuals who are physiologically predisposed to negative emotions are more creative if exposed to a negative emotional environment (Akinola and Mendes, 2008), providing a biological evidence for a link between depression and creativity. What is more, some studies have suggested that emotions may influence the encoding of information and the storage of memories from the outset (Plass and Kalyuga, 2019). In addition to seeing depression as an influential factor independent of creativity, depressive mood is part of informational functioning signal when individuals dealing with creative tasks (Baas et al., 2008). In contrast to positive emotions, which facilitates creative performance on funny tasks, negative mood helps individuals to achieve better creative performance on serious tasks, pushing individuals to work harder to meet standards (Ronald et al., 2007).

In summary, it is reasonable to hypothesize that:

H1 Depression is positively correlated with creativity.

While many studies have shown a link between depression and creativity, others have shown that the direct effect of depression on creativity is not significant (Silvia and Kimbrel, 2010), suggesting that no consistent and systematic conclusion exists about the internal mechanisms underlying the relationship between depression and creativity. Enhanced exploration of the mediation effect and moderate effect between depression and creativity may help uncover the relationship between the two.

\section{Psychological Resilience}

In the field of developmental psychology, psychological resilience refers to the ability of individuals to demonstrate better physical fitness, response and coping skills despite experiencing events that affect them greatly (Rutter, 2006; Huisman et al., 2017). 
Resilience enables individuals to find positive meaning in stress, to withdraw from negative emotions, to adapt to changing external stressors and to bounce back from the experience (Tugade and Fredrickson, 2004), which involves personal emotion and cognitive processes (Block and Kremen, 1996; Tugade and Fredrickson, 2004). Psychological resilience can be categorized as individual resilience or collective resilience (Rutter, 1999). From a behavioral perspective, psychological resilience can be viewed as a set of behaviors or attitudes and skills that enable effective coping with depression and stress (Sharpley et al., 2011, 2012). It can also be viewed as a stable personality trait that can influence emotion regulation processes (Masten, 2007; Hou and Ng, 2014). These multiple definitions reveal psychological resilience to be a multi-dimensional human ability (Dunn and Predescu, 2019) to adapt, recover and bounce back from adversity, stressful situations, threats or losses and to stimulate post-traumatic growth (van der Werff et al., 2013). The Rutter Model of Development suggests that there are four mechanisms by which mental resilience functions: (1) reducing the negative effects of risk factors; (2) minimizing collateral reactions to stressful events; (3) enhancing self-esteem and self-efficacy; and (4) providing opportunities and resources for individuals (Rutter, 1999).

Evidences suggest that psychological resilience plays a significant role in the regulation of negative emotions, helping people to emerge from emotional disturbances (e.g., depression, anxiety) and enhancing self-growth. When a stressor is present, an individual's psychological resilience can prevent psychological distress: for example, breast cancer patients acquired the resilience to cope with psychological problems that arise during treatment and effectively improved their quality of life (Sharpley et al., 2014; Ristevska-Dimitrovska et al., 2015; Liu et al., 2018). Similarly, adults with good education and social skills were more adaptable and resilient in the face of the general distress of the Great Depression and thus overcome its negative effects (Myklebust, 2000; Elder, 2001). In contrast, persons with low educational attainment have a higher risk of falling into depression when they fall victims of social events (e.g., Hurricane Katrina and the Gulf of Mexico oil spill). Psychological resilience is an important factor in reducing depression (Blackmon et al., 2016): according to a survey of survivors of the Japan earthquake and tsunami nuclear disaster, psychological resilience had an important moderating effect on depression and promotes post-traumatic growth (Kukihara et al., 2014). Similarly, in a longitudinal study of left-behind children in China, psychological resilience was shown to lessen the incidence of depression ( $\mathrm{Wu} \mathrm{Y}$. et al., 2015).

Based on the above evidence, we offer the following hypothesis:

\section{$\mathrm{H} 2 \mathrm{a}$ Psychological resilience is negatively correlated with depression.}

Evidences suggest that psychological resilience is a significant moderator against depression brought on by stressors (Luthar and Cicchetti, 2000). In the case of COVID-19, a global disaster, the depressive emotion is evident in the population, with a high prevalence of depression in college students and a moderate negative correlation between psychological resilience and depression (Taheri-Kharameh and Hazavehei, 2017; Karasar and Canli, 2020). Psychological resilience may be able to play an important role in human readjustment in the post-epidemic era, which can help individuals deal with depression, anxiety and other mood disorders that affect mental health (Osofsky et al., 2011; Shenesey and Langhinrichsen-Rohling, 2015). Therefore, it may enable them to solve everyday problems, to readjust to society and to create new opportunities (little-c). At work, for example, resilience can provide individuals with an internal mechanism to adapt, persist, and transcend, allowing them to maintain creativity through steady effort (Luthans et al., 2007). During learning, psychological resilience can provide learners with a powerful ability to challenge their environment, thereby eliciting positive emotions and motivation (Fredrickson et al., 2008; Chen and Padilla, 2019; Li and Jiang, 2020). Based on this evidence, we hypothesize that:

$\mathrm{H} 2 \mathrm{~b}$ Psychological resilience is positively correlated with creativity.

In summary, the second hypothesis is proposed:

$\mathrm{H} 2$ Psychological resilience plays a mediating role in the effect of depression on creativity.

\section{Rumination}

Rumination is a steady, ongoing, recurrent metacognitive process. During the process, individuals reflect on the meaning of negative emotions (Donaldson, 2005), including thoughts about the past, present and future (Papageorgiou and Wells, 2003a). With the help of Response Style Theory, it is known that males are more likely to adopt both problem-solving and attention-shifting responses, while females are more likely to adopt ruminative thinking (Smith and Alloy, 2009). It has been argued that rumination has a negative connotation, causing people to dwell on negative emotions rather than taking more effective problem-solving measures (Teismann et al., 2014). Individual's metacognition of ruminative thinking is the source of his or her negative emotions, i.e., the perceptions that individuals hold about ruminative thinking led to their own negative emotions (Conway et al., 2000). Excessive rumination may create a barrier to communication with others and suppress positive behaviors (Jain et al., 2007; Gebhardt et al., 2010). The process of rumination may be related to an individual's cognitive style, causing different individuals to have different attribution patterns and ways of coping with life (Calvete et al., 2015).

Rumination can be classified as of two main types: intrusive and deliberate (Cann et al., 2011). Intrusive rumination refers to unwelcome painful reflections that are automatic intrusions of negative emotions that cause deeper suffering. Deliberate rumination is more controlled: the individual takes an active role in the construction of meaning related to the stressor, problemsolving to reach understanding, thus potentially moderating depressed emotions (Watkins, 2008; Cann et al., 2010). Deliberate rumination can affect an individual's post-traumatic growth in response to a stressful event (Wu X. et al., 2015; 
Zhang et al., 2018). However, there is also evidence that the distinction between intrusive and deliberate rumination may be of little importance (Cann et al., 2011), and that the focus should be on rumination as a way of thinking and as a function (Papageorgiou and Wells, 2003b; Jain et al., 2007) rather than on its negative content (Verhaeghen et al., 2005). NolenHoeksema argues that depressive states are more persistent and severe in individuals who are under ruminative thinking (Nolen-Hoeksema, 1991; Nolen-Hoeksema et al., 1994). Overall, it is clear that there is a strong association between depression and rumination. Based on this, we can formulate the following hypothesis:

H3a Deliberate rumination is correlated with depression.

There are two dimensions of rumination, including reflection on emotions and the use of problem-solving strategies. It has been showed that rumination on problem-solving is positively correlated with creativity (Vahle-Hinz et al., 2017). Rumination allows individuals to generate ideas that can remain in consciousness for a long period of time, and the indecision may contribute to creativity (Cohen and Ferrari, 2010). Therefore, we hypothesize that:

$\mathrm{H} 3 \mathrm{~b}$ Deliberate rumination is correlated with creativity.

Rumination may also be served as a mediator or moderator in depression-related research. For example, rumination played a moderating role in the effect of neurotism on the relationship between depression and anxiety (Roelofs et al., 2008). In surveys of college students, rumination was found to moderate the correlation between temperament and depression (Liu et al., 2017) and mediate the relationship between social phobia and depression (Li et al., 2019). What is more, rumination explained and regulated gender differences in depression (Jose and Brown, 2007) and played a mediating role in the relationship between depression and gender (Treynor et al., 2003). A survey of victims of cyberviolence showed that deliberate rumination partially mediated the relationship between their experiences and depression (Liu et al., 2020). Moreover, a study which was to investigate relationship between stressful life events and sleep quality have found that rumination played a mediating role and psychological resilience played a mediating role, and both of them could moderate the effects of stress on sleep quality (Li et al., 2019). Therefore, the following hypotheses can be proposed:

$\mathrm{H} 3 \mathrm{c}$ Deliberate rumination may affect an individual's psychological resilience.

H3d Deliberate rumination may affect the relationship between the depression and psychological resilience of an individual.

Thus, we can distill from numerous studies that rumination generally acts as a mediator or moderator between a stressor and negative emotions (e.g., anxiety and depression). Rumination also has the potential to influence an individual's construction of emotional meaning, i.e., their psychological resilience, thereby influencing the transition from depression to post-traumatic growth. In summary, we propose the following hypothesis:
H3 Deliberate rumination may moderate the effects of psychological resilience on the relationship between depression and creativity.

\section{MATERIALS AND METHODS}

\section{Participants and Procedures}

This study was conducted at a polytechnic college in Guangdong Province, China, that has 13 teaching units, 44 undergraduate majors and more than 20,000 students, which was formally conducted between April 10 and June 15, 2020. A total of 918 persons completed the study questionnaire, of which 881 responses were valid. Among the respondents, 317 (36.0\%) were male and $564(64.0 \%)$ were female, all of whom were from the same grade.

The value of our research was confirmed when, prior to data collection, we learned from interviews that during the COVID-19 pandemic, respondents experienced varying degrees of depression. Many interviewees said that the progress of the pandemic had made them feel uneasy and that their studies and lives had been greatly affected.

\section{Data Collection}

This study was based on a correlational design, whereby data was collected by survey questionnaire. Between April 10 and June 15,2020 , students completed the survey by scanning QR codes during breaks in their college English classes. A QR code is a black-and-white graphic recording of data symbol information with a specific geometric pattern distributed regularly on a two-dimensional plane (Tan et al., 2018), which is widely used and accepted in China for activities such as online payment, daily travel and data entry. Participants completed the questionnaire voluntarily.

The questionnaire consisted of five sections: (a) Demographic Information, (b) Depression Scale, (c) Runco Ideational Behavior Scale, (d) Psychological Resilience Scale, and (e) Deliberate Rumination Scale. The demographic information included gender, home address and major. The scales in the questionnaire were originally designed in English, and so back-translation was used to improve the accuracy of the questions: the researcher translated the questionnaire from English to Chinese, then another researcher retranslated the Chinese version into English, and finally a third researcher compared the two versions and adjusted the scales to eliminate discrepancies.

\section{Measures}

\section{Depression Scale}

Depression was measured by the Depression Anxiety Stress Scales (DASS-21), which consists of seven items created by Lovibond and Lovibond (1995) and modified by Antony et al. (1998). DASS-21 is scored on a 4-point scale that assesses the participant's various induced negative affective states. The criteria are " 1 " for did not apply to me at all, " 2 " for applied to me to some degree, " 3 " for applied to me to a considerable degree and " 4 " for applied to me very much, with higher scores indicating a higher level of 
depression. In the present study, the Cronbach's alpha coefficient for DASS-21 was 0.882 .

\section{Runco Ideational Behavior Scale}

Creativity was assessed by the Runco Ideational Behavior Scale (Runco et al., 2001; Plucker et al., 2010; Tsai, 2015), which has 23 items. The scale focuses on individuals' self-report level of creative behavior from everyday life, using a 5-point scale where " 1 " is strongly disagree, "2" is mostly disagree, " 3 " is uncertain, " 4 " is mostly agree and " 5 " is strongly agree. In the present study, the Cronbach's alpha coefficient for the Runco Ideational Behavior Scale was 0.938 .

\section{Psychological Resilience Scale}

Psychological resilience was measured by the Psychological Resilience Scale, which has 27 items (Connor and Davidson, 2003) divided into five dimensions: goal focus, emotional control, positive cognition, family support, and interpersonal assistance (Hu and Gan, 2008). The questionnaire is scored on a 5-point scale that assesses the participant's feelings about, reactions to and agreement with the indicators. The criteria are "1" for completely inconsistent, "2" for relatively inconsistent, "3" for ambiguous, " 4 " for relatively consistent and " 5 " for completely consistent. In the present study, the Cronbach's alpha coefficient for the Psychological Resilience Scale was 0.860 .

\section{Deliberate Rumination Scale}

Deliberate rumination was assessed by the Rumination Scale (Cann et al., 2011), which is divided into two dimensions: intrusive rumination and deliberate rumination (Cann et al., 2011). In this study, the deliberate rumination section of the Rumination Scale was selected, which consists of 10 items and is scored on a 4-point scale, with "1" for not at all, "2" for occasionally, " 3 " for frequently and " 4 "for always. In the present study, the Cronbach's alpha coefficient for the deliberate rumination section of the Rumination Scale was 0.913 .

\section{Statistical Analyses}

The analysis tool used in this study was IBM SPSS 23.0.

First, we performed Harman's single factor test to examine common method bias (Podsakoff et al., 2003). The results of unrotated principal component analysis showed that 21 factors had eigenvalues greater than 1 , of which the contribution to the total variance was $65.811 \%$. The first factor accounted for only $17.830 \%$, which is far below the critical criterion of $40 \%$ ( $\mathrm{Li}$, 2018), indicating that there was no significant common method bias. In other words, the variation between the independent and dependent variables was caused more by difference in the nature of variables than by the methods of data collection and measurement.

Following the test of common method bias, descriptive statistical analysis was performed: the mean and standard deviation of each variable were calculated to observe the trend of concentration and dispersion. Then, Pearson product-moment correlation coefficients were calculated to test the correlation on all variables (see Table $\mathbf{1}$ ).

Finally, PROCESS V3.3 (Hayes, 2013) was used to test the mediation model (Model 4) and the moderating mediation model (Model 7). For both models gender was used as a control variable. Indicators of indirect effects were tested using a bias-corrected bootstrapping ( $n=5,000)$ with $95 \%$ confidence intervals. When the $95 \%$ confidence interval does not include zero, it indicates that the parameter is statistically significant (Shrout and Bolger, 2002).

\section{RESULTS}

\section{Descriptive Statistics and Correlation Analysis}

Descriptive analyses and correlations among variables are shown in Table 1.

As expected, depression and creativity were positively and weakly correlated in college students $(r=0.085, p<0.05)$; depression and psychological resilience were significantly and negatively correlated $(r=-0.462, p<0.01)$; psychological resilience was significantly and positively correlated with creativity $(r=0.198, p<0.01)$; deliberate rumination was positively correlated with depression $(r=0.138, p<0.01)$; deliberate rumination showed a positive correlation with psychological resilience $(r=0.078, p<0.05)$; and deliberate rumination showed a positive correlation with creativity $(r=0.288, p<0.05)$. Therefore, the correlation of study variables aligned with the hypotheses.

\section{Mediating Effect of Psychological Resilience}

Mediation analysis was carried out using depression as the independent variable, creativity as the dependent variable and psychological resilience as the mediator.

TABLE 1 | Means, standard deviations, and correlations among variables.

\begin{tabular}{|c|c|c|c|c|c|c|c|}
\hline & $M$ & $S D$ & (1) & (2) & (3) & (4) & (5) \\
\hline (2) Depression & 1.635 & 0.568 & $-0.140^{\star \star}$ & - & & & \\
\hline (4) PR & 3.417 & 0.443 & $-0.076^{\star}$ & $-0.462^{\star \star}$ & $0.198^{\star \star}$ & - & \\
\hline (5) DR & 2.012 & 0.520 & $0.071^{*}$ & $0.138^{\star \star}$ & $0.288^{\star}$ & $0.078^{*}$ & - \\
\hline
\end{tabular}

${ }^{*} p<0.05,{ }^{* *} p<0.01,{ }^{* * *} p<0.001$.

$P R$, psychological resilience; $D R$, deliberate rumination. 
TABLE 2 | Testing the mediating effect of depression on creativity.

\begin{tabular}{|c|c|c|c|c|c|c|c|c|c|}
\hline \multirow[t]{2}{*}{ Preditors } & \multicolumn{4}{|c|}{ On psychological resilience } & & \multicolumn{4}{|c|}{ On creativity } \\
\hline & $\beta$ & SE & $\mathbf{t}$ & $95 \% \mathrm{Cl}$ & & $\beta$ & SE & $\mathbf{t}$ & $95 \% \mathrm{Cl}$ \\
\hline Gender & 0.011 & 0.028 & 0.385 & {$[-0.044,0.066]$} & & -0.032 & 0.038 & -0.840 & {$[-0.108,0.043]$} \\
\hline Depression & -0.359 & 0.024 & $-15.216^{\star \star \star}$ & {$[-0.406,-0.31]$} & & 0.219 & 0.037 & $5.994^{\star \star \star}$ & {$[0.147,0.291]$} \\
\hline PR & - & - & & - & - & 0.384 & 0.046 & $8.264^{\star \star \star}$ & {$[0.291,0.475]$} \\
\hline $\mathrm{R} 2$ & 0.213 & - & & - & - & 0.080 & - & & - \\
\hline $\mathrm{F}$ & 118.985 & - & & - & - & 25.235 & - & & - \\
\hline \multirow[t]{2}{*}{ Direct effect of $X$ on $Y$} & $\beta$ & SE & $\mathbf{t}$ & 95\% LLCI & Indirect effect (s) of $X$ on $Y$ & $\beta$ & & SE & $95 \%$ BootCl \\
\hline & 0.219 & 0.037 & $5.994^{\star \star \star}$ & {$[0.147,0.291]$} & & -0.138 & & 0.020 & {$[-0.180,-0.100]$} \\
\hline
\end{tabular}

${ }^{*} p<0.05,{ }^{* *} p<0.01,{ }^{* * *} p<0.001$. PR, psychological resilience.

Analyses conducted by PROCESS Model 4, N = 881. Gender was dummy coded (1, female, 0, male).

Since gender may affect variables, it was used as a control variable. Gender was transformed into a dummy variable before entering the mediation model. When gender was controlled, the correlation coefficient between variables changed very little, so it had little effect on the overall mediation model.

As is shown in Table 2, the total effect of depression on creativity was statistically significant $(\beta=0.219, S E=0.037$, $P<0.001)$, indicating that an appropriate depressive mood had a positive predictive effect on creativity. This predictive effect remained significant when psychological resilience was added $(\beta=-0.138, S E=0.020,95 \% \mathrm{CI}=[-0.180,-0.100])$. Depression had a significant negative effect on psychological resilience $(\beta=-0.359, S E=0.024, P<0.001)$, and psychological resilience had a significant positive effect on creativity $(\beta=0.384, S E=0.046, P<0.001)$. Psychological resilience mediated the model through its negative association with depression.

In addition, bias-corrected bootstrapping revealed further moderating mediation effects, with confidence intervals (95\%) that did not include zero values between the upper and lower bounds (see Table 2). This suggests that depression can have a direct effect on creativity as well as an indirect effect on creativity through psychological resilience, with direct effects accounting for $37.052 \%$ of the total effect and mediating effects for $62.948 \%$, respectively.

\section{Moderated Mediation Effects}

Gender also served as a control variable in the mediation model test conducted by PROCESS model7.

Table 3 shows that had a significant moderating effect on psychological resilience $(\beta=-0.104, t=-2.863, P<0.01)$. To better test the moderated mediation model, the scores for deliberate rumination were divided into high (1 standard deviation above the median), medium and low groups (1 standard deviation below the median) (Table 4), and a simple slope test was performed (Figure 1). The results indicated (Figure 1) that depression combined with high deliberate rumination $(\beta=-0.426, S E=0.029, p<0.001,95 \%$ $\mathrm{CI}=[-0.484,-0.369])$ was more strongly associated with psychological resilience than depression combined with low deliberate rumination $(\beta=-0.318, S E=0.031, p<0.001,95 \%$ $\mathrm{CI}=[-0.379,-0.257])$.

Figure 2 shows the moderated mediation model, in which deliberate rumination moderated the effects of depression on psychological resilience, and deliberate rumination regulates just the first stage of the mediation process.

\section{DISCUSSION}

\section{Discussion of Results}

In this study, we developed a moderated mediation model of the relationship between depression and creativity among college students during the pandemic of COVID-19. It was found that: (1) depression is positively correlated with creativity; (2) the positive association between depression and creativity is partially mediated by psychological resilience; and (3) deliberate rumination is able to play a moderating role in the direct effect of depression on creativity. These results are consistent with the proposed hypotheses and previous findings.

First, the results were consistent with $\mathrm{H} 1$ and the existing literature, revealing that depression is positively correlated with creativity. This finding indicates that depression does not just generate negative effects but also may prompt an individual to be more creative (De Dreu et al., 2008; Nijstad et al., 2010). During the quarantine of COVID-19 outbreak, individuals' physical activities were significantly reduced (Khosravi, 2020), while research has proven that if regular physical activity is performed in a confined environment, it can prevent and alleviate individual's depression and anxiety (Takács, 2014). Therefore, the lack of physical activity during the confinement may exacerbate depression and anxiety (Ingram et al., 2020; Lopez et al., 2020). And when a person is of depression, it may affect the one's ability to cope with life events, thus affecting daily creativity (little-c). The dual pathway to creativity model developed by De Dreu et al. (2008), suggests that mood states primarily influence creativity through cognitive flexibility and cognitive persistence (De Dreu et al., 2008; Nijstad et al., 2010): activating negative moods improves cognitive persistence, making it possible to better perform analytical tasks (Huntsinger and Ray, 2016). 
TABLE 3 | Examination of the moderating effect of depression on creativity.

\begin{tabular}{|c|c|c|c|c|c|c|c|c|}
\hline \multirow[t]{2}{*}{ Preditors } & \multicolumn{4}{|c|}{ On psychological resilience } & \multicolumn{4}{|c|}{ On creativity } \\
\hline & $\beta$ & SE & $\mathbf{t}$ & $95 \% \mathrm{Cl}$ & $\beta$ & SE & $\mathbf{t}$ & $95 \% \mathrm{Cl}$ \\
\hline Gender & -0.005 & 0.028 & -0.171 & {$[-0.059,0.049]$} & -0.032 & 0.038 & -0.084 & {$[-0.108,0.043]$} \\
\hline Depression & -0.372 & 0.024 & $-15.81^{\star \star \star}$ & {$[-0.418,-0.326]$} & 0.219 & 0.037 & $5.994^{\star \star \star}$ & {$[0.147,0.291]$} \\
\hline DR & 0.136 & 0.026 & $5.269^{\star \star \star}$ & {$[0.086,0.187]$} & & & & \\
\hline PR & & & & & 0.384 & 0.046 & $8.264^{\star \star \star}$ & {$[0.292,0.475]$} \\
\hline Depression $\times$ DR & -0.104 & 0.036 & $-2.863^{\star \star}$ & {$[-0.176,-0.033]$} & & & & \\
\hline $\mathrm{R} 2$ & 0.241 & - & - & - & 0.079 & - & & - \\
\hline $\mathrm{F}$ & 69.398 & - & - & - & 25.235 & - & & - \\
\hline
\end{tabular}

Analyses conducted using PROCESS model 7 with $N=881$. Gender is dummy coded (1, female, 0 , male).

$P R$, psychological resilience; $D R$, deliberate rumination. $p<0.05,{ }^{* *} p<0.01,{ }^{* * *} p<0.001$.

TABLE 4 | Results for conditional indirect effect of depression on creativity via PR across levels of deliberate rumination.

\begin{tabular}{|c|c|c|c|c|c|}
\hline Moderator & Level & Effect size & Boot SE & LL $95 \% \mathrm{Cl}$ & UL $95 \% \mathrm{Cl}$ \\
\hline \multirow[t]{3}{*}{ Deliberate rumination } & Low (M-1SD) & -0.318 & 0.031 & -0.379 & -0.257 \\
\hline & Medium (M) & -0.372 & 0.024 & -0.418 & -0.326 \\
\hline & High $(M+1 S D)$ & -0.426 & 0.029 & -0.484 & -0.369 \\
\hline
\end{tabular}

Bootstrap sample size = 5,000. Low, 1 SD below the mean. High, 1 SD above the mean. PR, psychological resilience; DR, deliberate rumination.

These findings are consistent with the cognitive tuning theory, which suggests that the bar for problem-solving effectiveness may be set higher when people are in a negative mood state than when they are in a positive mood state (Schwarz, 2000). An individual in negative affect may prolong the process of gathering and processing problem-relevant information, thereby enhancing creativity (Fredrickson and Branigan, 2005; Lin et al., 2013). Similarly, according to the cognitive model of depression, depressive thinking is related to bottom-up cognitive processing (Disner et al., 2011; Kwak et al., 2016), which enables negative emotions to generate powerful self-reflective thoughts and perseverance, leading to creative performances (Akinola and Mendes, 2008; De Dreu et al., 2008).

The results of the present study also validated H2. First, the results showed that depression negatively predicts psychological resilience, which is consistent with previous studies (Karasar and Canli, 2020) revealing that strong psychological resilience may alleviate depression (Taheri-Kharameh and Hazavehei, 2017). In other words, psychological resilience has been shown to have an important adaptive, regulatory function in recovery from depression (Li et al., 2015; Wojujutari et al., 2019) by allowing individuals' resistance and self-protection to come into play (Rutter, 2018). As well, greater psychological resilience can stimulate positive emotions in individuals that enable them to emerge from pain (Ong et al., 2010). Second, psychological resilience is a positive predictor of creativity, which is consistent with psychological and sociological findings that when individuals have strong psychological resilience, their problem-solving stamina and resilience are at a higher level, thus promoting creativity. Creativity is associated with the social component of psychological resilience because creative activity, in turn, psychological resilience is supported by the social environment and relationships that reinforce participation in

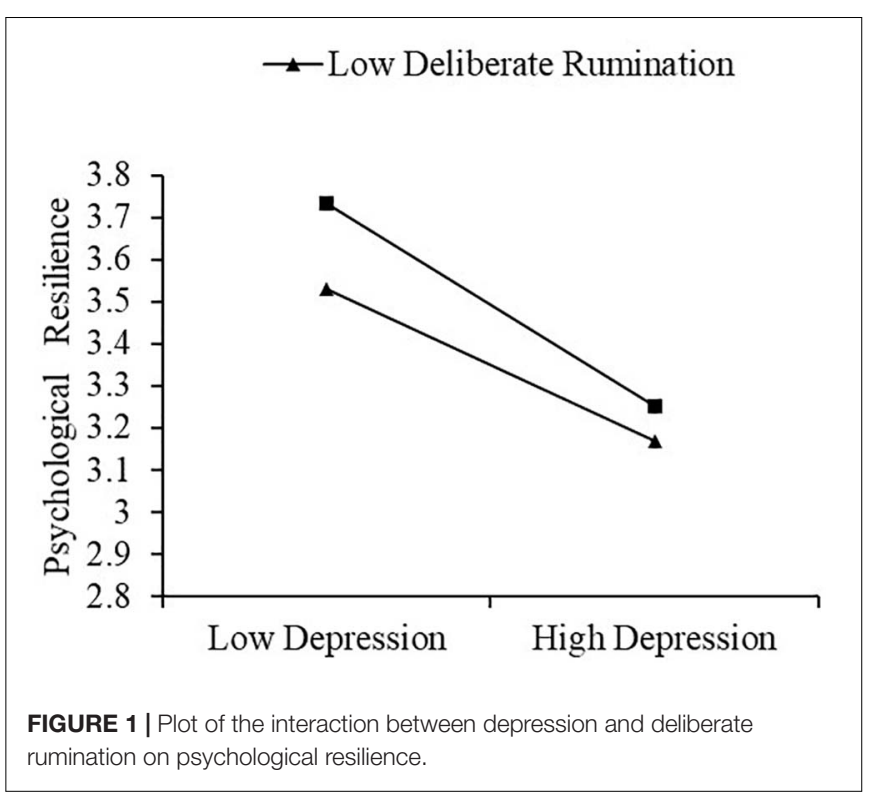

creative activity, which means that creative social engagement and psychological resilience are mutually supportive (Hertzog et al., 2008; McFadden and Basting, 2010).

Furthermore, we found that psychological resilience can act as a mediator between depression and creativity, which supports H2. Neurologically, psychological resilience appears to be related to emotional processing (Shi et al., 2019). More precisely, psychological resilience is associated with functional connectivity between the left orbitofrontal gyrus and the left inferior frontal gyrus of the brain, which flexibly use emotional resources and control interest processing (Shi et al., 2019). Thus, individual with high resilience may be able to capitalize 


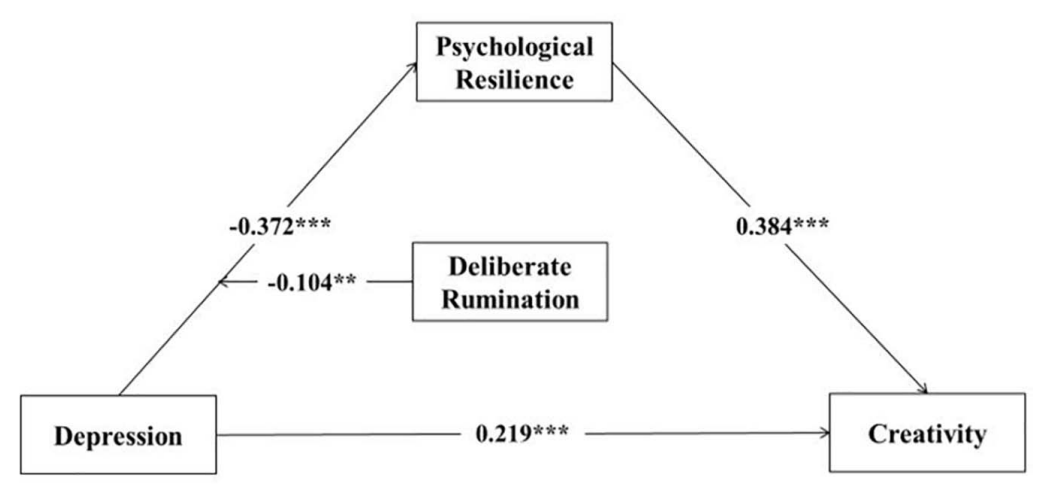

FIGURE 2 | The moderated mediation model that controls for gender. ${ }^{\star} p<0.05 ;{ }^{* *} p<0.01 ;{ }^{* * *} p<0.001$.

on their emotional resources in the face of adversity or threat (Debbane et al., 2017), enabling them to survive and thrive as they adjust positively to adversity (Sweetman et al., 2011). Therefore, it can be inferred that psychological resilience may play an important role in re-adaptation during the post-pandemic era, helping individuals deal with depression, anxiety and other mood disorders that affect mental health (Osofsky et al., 2011; Shenesey and Langhinrichsen-Rohling, 2015). Psychological resilience may also prompt individuals to find better solutions to problems of daily life and readjustment to society, creating new opportunities (little-c).

Finally, our findings are consistent with $\mathrm{H} 3$, revealing a correlation between deliberate rumination and depression, psychological resilience and creativity, suggesting that deliberate rumination plays a moderating role in the mediation model. The study results show that deliberate rumination moderates the effects of psychological resilience on the relationship between depression and creativity, which echoes the findings of previous studies (Rider Mundey et al., 2018; Kim and Bae, 2019). The implication is that, when individuals are in depression, those who have high levels of deliberate rumination may analyze depression metacognitively, generating powerful self-reflection and perseverance (Akinola and Mendes, 2008; De Dreu et al., 2008). This process may turn negative emotions into positive constructs of meaning to help individuals achieve post-traumatic growth, thereby increasing their psychological resilience (Solem et al., 2016). In reality, after a longer period of depressed emotional state, using psychological resilience as a mediating path, college students are often able to emerge from the trauma and grow. At the same time, deliberate rumination further strengthens psychological resilience, which ultimately acts on individual's creativity.

\section{Discussion of Implications}

From a theoretical perspective, this study establishes a link between depression and creativity, thus deepening the discussion of the effect of depression on creativity and enhancing related research findings. In addition, we have found that psychological resilience mediates the effects of depression on creativity and that, in turn. deliberate rumination moderates the mediating effect of psychological resilience. This finding implies that college students suffering from depression may enhance their ability to adjust positively and to cope with challenges by increasing their psychological resilience, which could allow them to express their creative potential in their daily life or in their areas of expertise.

From a practical perspective, the relationship revealed between the four variables by this study may help researchers better understand the mechanisms by which depression stimulates creativity, thus providing different entry points for emotional healing and psychological guidance.

\section{Limitations and Future Direction}

The limitations of this study are apparent. First, the study is a cross-sectional study, so not enough has been done on longitudinal studies. Second, all participants were from the same university, and the group comprised mainly college students, therefore, the sample of this study is not universally representative and the results of this study cannot be generalized. This study is only used as an independent research study for reference and does not have the significance of generalizing the results.

Future researchers might carry out longitudinal research to follow up with participants. In addition, researchers could explore which other mediating variables may frame the effects of depression on creativity and whether the effects of depression differ according to dimensions of creativity.

The mechanisms and cognitive processes associated with depression and its effects on creativity are still contested, but this study may provide empirical evidence and insights for future researchers.

\section{CONCLUSION}

This study explored the relationship between depression and creativity, the mediating effect of psychological resilience between the two and the moderating effect of deliberate rumination on psychological resilience. The results suggest that depression is a positive predictor of creativity and may promote creativity to some extent. Further, individuals with greater psychological resilience are more creative than those with less 
psychological resilience, as it is a question of whether they can and to what extent they can effectively use depression as an emotional resource. Last, an individual's level of deliberate rumination moderates the mediating process, especially at the stage where depression is associated with psychological resilience. These findings advance understanding of the mechanisms that operate between depression and creativity.

\section{DATA AVAILABILITY STATEMENT}

The raw data supporting the conclusions of this article will be made available by the authors, without undue reservation.

\section{ETHICS STATEMENT}

The studies involving human participants were reviewed and approved by the Institutional Ethics Committee of

\section{REFERENCES}

Acar, S., and Sen, S. (2013). A multilevel meta-analysis of the relationship between creativity and schizotypy. Psychol. Aesthet. Creat. Arts 7, 214-228. doi: 10.1037/ a0031975

Akinola, M., and Mendes, W. B. (2008). The dark side of creativity: biological vulnerability and negative emotions lead to greater artistic creativity. Pers. Soc. Psychol. Bull. 34, 1677-1686. doi: 10.1177/0146167208323933

Andreasen, N. C. (1987). Creativity and mental illness: prevalence rates in writers and their first-degree relatives. Am. J. Psychiatry 144, 1288-1292. doi: 10.1176/ ajp.144.10.1288

Antony, M. M., Bieling, P. J., Cox, B. J., Enns, M. W., and Swinson, R. P. (1998). Psychometric properties of the 42-item and 21-item versions of the depression anxiety stress scales in clinical groups and a community sample. Psychol. Assess. 10, 176-181. doi: 10.1037/1040-3590.10.2.176

Baas, M., De Dreu, C. K., and Nijstad, B. A. (2008). A meta-analysis of 25 years of mood-creativity research: hedonic tone, activation, or regulatory focus? Psychol. Bull. 134, 779-806. doi: 10.1037/a0012815

Bartoszek, A., Walkowiak, D., Bartoszek, A., and Kardas, G. (2020). Mental wellbeing (depression, loneliness, insomnia, daily life fatigue) during COVID-19 related home-confinement - a study from Poland. Int. J. Environ. Res. Publ. Health 17:7417. doi: 10.3390/ijerph17207417

Beck, J. G., Novy, D. M., Diefenbach, G. J., Stanley, M. A., Averill, P. M., and Swann, A. C. (2003). Differentiating anxiety and depression in older adults with generalized anxiety disorder. Psychol. Assess. 15, 184-192. doi: 10.1037/10403590.15.2.184

Blackmon, B. J., Lee, J., Cochran, D. M., Kar, B., Rehner, T. A., and Baker, A. M. (2016). Adapting to life after Hurricane Katrina and the deepwater horizon oil spill: an examination of psychological resilience and depression on the Mississippi Gulf Coast. Soc. Work Publ. Health 32, 165-176. doi: 10.1080/ 19371918.2016.1188746

Block, J., and Kremen, A. M. (1996). IQ and ego-resiliency: conceptual and empirical connections and separateness. J. Pers. Soc. Psychol. 70, 349-361. doi: 10.1037/0022-3514.70.2.349

Cadle, C. R. (2015). A completion mindset: bridging the gap between creative thinking and creativity. Psychol. Aesthet. Creat. Arts 9, 172-177. doi: 10.1037/ aca0000019

Calvete, E., Orue, I., and Nankin, B. L. (2015). Cross-Lagged associations among ruminative response style, stressors and depressive symptoms in adolescents. J. Soc. Clin. Psychol. 34, 203-220. doi: 10.1521/jscp.2015.34.3.203

Cann, A., Calhoun, L. G., Tedeschi, R. G., and Solomon, D. T. (2010). Posttraumatic growth and depreciation as independent experiences and predictors of well-being. J. Loss Trauma 15, 151-166. doi: 10.1080/ 15325020903375826
School of Geography, South China Normal University. The patients/participants provided their written informed consent to participate in this study.

\section{AUTHOR CONTRIBUTIONS}

YX and WZ designed the research and reviewed and edited the manuscript. JS, YX, WZ, and DH reviewed the literature and analyzed the data. YX, JS, WZ, YZ, XW, JW, and DH wrote the manuscript. All authors have read and agreed to the published version of the manuscript.

\section{FUNDING}

This research was funded by the Guangdong Planning Office of Philosophy and Social Science (grant no. GD20CJY19).

Cann, A., Calhoun, L. G., Tedeschi, R. G., Triplett, K. N., Vishnevsky, T., and Lindstrom, C. M. (2011). Assessing posttraumatic cognitive processes: the event related rumination inventory. Anx. Stress Coping 24, 137-156. doi: 10.1080/ 10615806.2010.529901

Chen, X., and Padilla, A. M. (2019). Emotions and creativity as predictors of resilience among L3 learners in the Chinese educational context. Curr. Psychol. [Epub ahead of print]. doi: 10.1007/s12144-019-00581-7

Cohen, J. R., and Ferrari, F. R. (2010). Take some time to think this over: the relation between rumination, indecision and creativity. Creat. Res. J. 22, 68-73. doi: 10.1080/10400410903579601

Connor, K. M., and Davidson, J. R. T. (2003). Development of a new resilience scale: the Connor-Davidson Resilience Scale (CD-RISC). Depress. Anx. 18, 76-82. doi: 10.1002/da.10113

Conway, M., Csank, P., Holm, S. L., and Blake, C. K. (2000). On assessing individual differences in rumination on sadness. J. Pers. Assess. 75, 404-425. doi: 10.1207/ S15327752JPA7503_04

Corazza, G. E. (2016). Potential originality and effectiveness: the dynamic definition of creativity. Creat. Res. J. 28, 258-267. doi: 10.1080/10400419.2016. 1195627

Cox, D. W., Kealy, D., Kahn, J. H., Wojcik, K. D., Joyce, A. S., and Ogrodniczuk, J. S. (2019). The attenuating effect of depression symptoms on negative-affect expression: individual and group effects in group psychotherapy for personality disorders. J. Counsel. Psychol. 66, 351-361. doi: 10.1037/cou0000335

De Dreu, C. K. W., Baas, M., and Nijstad, B. A. (2008). Hedonic tone and activation level in the mood-creativity link: toward a dual pathway to creativity model. J. Pers. Soc. Psychol. 94, 739-756. doi: 10.1037/0022-3514.94.5.739

Debbane, M., Badoud, D., Sander, D., Eliez, S., Luyten, P., and Vrticka, P. (2017). Brain activity underlying negative self- and other-perception in adolescents: the role of attachment-derived self-representations. Cogn. Affect. Behav. Neurosci. 17, 554-576. doi: 10.3758/s13415-017-0497-9

Dhar, B. K., Ayittey, F. K., and Sarkar, S. M. (2020). Impact of COVID-19 on psychology among the university students. Glob. Challeng. 4:2000038. doi: 10. $1002 /$ gch 2.202000038

Ding, G., Liu, H., Huang, Q., and Gu, J. (2019). Enterprise social networking usage as a moderator of the relationship between work stressors and employee creativity: a multilevel study. Inform. Manag. 56, 103165. doi: 10.1016/j.im.2019. 04.008

Disner, S. G., Beevers, C. G., Haigh, E. A. P., and Beck, A. T. (2011). Neural mechanisms of the cognitive model of depression. Nat. Rev. Neurosci. 12, 467-477. doi: 10.1038/nrn3027

Donaldson, C. (2005). Depressive rumination: nature, theory \& treatment. Br. J. Clin. Psychol. 44, 140-141. doi: 10.1348/014466505x103762

Dunn, L. B., and Predescu, I. (2019). Resilience: a rich concept in need of research. Comment on: "Neurocognitive correlates of resilience in late-life depression" 
(by Laird et al.). Am. J. Geriatr. Psychiatry 27, 18-20. doi: 10.1016/j.jagp.2018. 10.002

Elder, G. H. (2001). Families, social change and individual lives. Marr. Fam. Rev. 31, 177-192. doi: 10.1300/J002v31n01_08

Fredrickson, B. L., and Branigan, C. (2005). Positive emotions broaden the scope of attention and thought-action repertoires. Cogn. Emot. 19, 313-332. doi: $10.1080 / 02699930441000238$

Fredrickson, B. L., Cohn, M. A., Coffey, K. A., Pek, J., and Finkel, S. M. (2008). Open hearts build lives: positive emotions, induced through loving-kindness meditation, build consequential personal resources. J. Pers. Soc. Psychol. 95, 1045-1062. doi: 10.1037/a0013262

Gardner, H. (1993). "Seven creators of the modern era," in Creativity, ed. J. Brockman (New York, NY: Simon \& Schuster), 28-47.

Gebhardt, W. A., Van Der Doef, M. P., Massey, E. K., Verhoeven, C. J. M., and Verkuil, B. (2010). Goal commitment to finding a partner and satisfaction with life among female singles: the mediating role of rumination. J. Health Psychol. 15, 122-130. doi: $10.1177 / 1359105309346212$

Goswami, A. (1996). Creativity and the quantum: a unified theory of creativity. Creat. Res. J. 9, 47-61. doi: 10.1207/s15326934crj0901_5

Guilford, J. P. (1950). Creativity. Am. Psychol. 5, 444-454. doi: 10.1037/h0063487

Hah, J. (2006). Problem finding and creativity. Knowl. Manag. Res. 7, 1-12.

Han, W., Feng, X., Zhang, M., Peng, K., and Zhang, D. (2019). Mood states and everyday creativity: employing an experience sampling method and a day reconstruction method. Front. Psychol. 10:1698. doi: 10.3389/fpsyg.2019.01698

Hayes, A. F. (2013). Introduction to Mediation, Moderation, and Conditional Process Analysis: A Regression-Based Approach. New York, NY: Guilford Press.

Hertzog, C., Kramer, A. F., Wilson, R. S., and Lindenberger, U. (2008). Enrichment effects on adult cognitive development: can the functional capacity of older adults be preserved and enhanced? Psychol. Sci. Publ. Interest 9, 1-65. doi: 10.1111/j.1539-6053.2009.01034.x

Hou, W. K., and Ng, S. M. (2014). Emotion-focused positive rumination and relationship satisfaction as the underlying mechanisms between resilience and psychiatric symptoms. Pers. Indiv. Differ. 71, 159-164. doi: 10.1016/j.paid.2014. 07.032

Hu, Y., and Gan, Y. (2008). Development and psychometric validity of the resilience scale for Chinese adolescents. Acta Psychol. Sin. China 40, 902-912.

Huisman, M., Klokgieters, S. S., and Beekman, A. T. F. (2017). Successful ageing, depression and resilience research; a call for a priori approaches to investigations of resilience. Epidemiol. Psychiatr. Sci. 26, 574-578. doi: 10.1017/ s2045796017000348

Huntsinger, J. R., and Ray, C. (2016). A flexible influence of affective feelings on creative and analytic performance. Emotion 16, 826-837. doi: 10.1037/ emo0000188

Ingram, J., Maciejewski, G., and Hand, C. J. (2020). Changes in diet, sleep, and physical activity are associated with differences in negative mood during covid-19 lockdown. Front. Psychol. 11:588604. doi: 10.3389/fpsyg.2020.588604

Isen, A. M., Daubman, K. A., and Nowicki, G. P. (1987). Positive affect facilitates creative problem solving. J. Pers. Soc. Psychol. 52, 1122-1131. doi: 10.1037/00223514.52.6.1122

Jain, S., Shapiro, S. L., Swanick, S., Roesch, S. C., Mills, P. J., Bell, I., et al. (2007). A randomized controlled trial of mindfulness meditation versus relaxation training: effects on distress, positive states of mind, rumination and distraction. Ann. Behav. Med. 33, 11-21. doi: 10.1207/s15324796abm3301_2

Jose, P. E., and Brown, I. (2007). When does the gender difference in rumination begin? Gender and age differences in the use of rumination by adolescents. J. Youth Adoles. 37, 180-192. doi: 10.1007/s10964-006-9166-y

Karasar, B., and Canli, D. (2020). Psychological resilience and depression during the COVID-19 pandemic in Turkey. Psychiatr. Danub. 32, 273-279. doi: 10. 24869/psyd.2020.273

Kaufmann, G., and Vosburg, S. K. (1997). "Paradoxical" mood effects on creative problem-solving. Cogn. Emot. 11, 151-170. doi: 10.1080/026999397379971

Khosravi, M. (2020). Covid-19 quarantine: two-way interaction between physical activity and mental health. Eur. J. Transl. Myol. 30:9509. doi: 10.4081/ejtm.2020. 9509

Kim, E., and Bae, S. (2019). Gratitude moderates the mediating effect of deliberate rumination on the relationship between intrusive rumination and posttraumatic growth. Front. Psychol. 10:2665. doi: 10.3389/fpsyg.2019.02665
Kim, M. J., Choi, J. N., and Lee, K. (2016). Trait affect and individual creativity: moderating roles of affective climate and reflexivity. Soc. Behav. Pers. 44, 1477-1498. doi: 10.2224/sbp.2016.44.9.1477

Kukihara, H., Yamawaki, Y., Uchiyama, K., Arai, S., and Horikawa, E. (2014). Trauma, depression and resilience of earthquake/tsunami/nuclear disaster survivors of Hirono, Fukushima, Japan. Psychiatry Clin. Neurosci. 68, 524-533. doi: $10.1111 / p c n .12159$

Kwak, Y. T., Yang, Y. S., and Koo, M.-S. (2016). Depression and cognition. Dement. Neurocogn. Disord. 15, 103-109. doi: 10.12779/dnd.2016.15.4.103

Kyaga, S., Lichtenstein, P., Boman, M., Hultman, C., Långström, N., and Landén, M. (2018). Creativity and mental disorder: family study of 300000 people with severe mental disorder. Br. J. Psychiatry 199, 373-379. doi: 10.1192/bjp.bp.110. 085316

Lai, Y., Peng, S., Huang, P., and Chen, H. (2020). The impact of affective states and affective shifts on creative ideation and evaluation. J. Creat. Behav. 55, 130-144. doi: $10.1002 /$ jocb. 440

Lee, S. Y., Florida, R., and Acs, Z. (2004). Creativity and entrepreneurship: a regional analysis of new firm formation. Reg. Stud. 38, 879-891. doi: 10.1080/ 0034340042000280910

Leschziner, V., and Brett, G. (2019). Beyond two minds: cognitive, embodied and evaluative processes in creativity. Soc. Psychol. Q. 82, 340-366. doi: 10.1177/ 0190272519851791

Li, C., and Jiang, G. (2020). Positive psychology perspectives on foreign language learning and teaching. Int. J. Biling. Educ. Biling. 23, 244-246. doi: 10.1080/ 13670050.2017 .1350279

Li, J., Theng, Y. L., and Foo, S. (2015). Does psychological resilience mediate the impact of social support on geriatric depression? An exploratory study among Chinese older adults in Singapore. Asian J. Psychiatry 14, 22-27. doi: 10.1016/j.ajp.2015.01.011

$\mathrm{Li}, \mathrm{Y}$. (2018). The impact of parental rearing style on learning engagement among senior high school students: a serial mediation effect model [in Chinese]. Psychol. Dev. Educ. China 34, 576-585. doi: 10.16187/j.cnki.issn1001-4918. 2018.05.08

Li, Y., Gu, S., Wang, Z., Li, H., Xu, X., Zhu, H., et al. (2019). Relationship between stressful life events and sleep quality: rumination as a mediator and resilience as a moderator. Front. Psychiatry 10:348. doi: 10.3389/fpsyt.2019.00348

Lin, W., Tsai, P. H., Lin, H., and Chen, H. (2013). How does emotion influence different creative performances? The mediating role of cognitive flexibility. Cogn. Emot. 28, 834-844. doi: 10.1080/02699931.2013.854195

Liu, C., Liu, Z., and Yuan, G. (2020). The longitudinal influence of cyberbullying victimization on depression and posttraumatic stress symptoms: the mediation role of rumination. Arch. Psychiatr. Nurs. 34, 206-210. doi: 10.1016/j.apnu.2020. 05.002

Liu, M., Jiang, Y., Wang, X., Liu, Q., and Wu, H. (2017). The role of rumination and stressful life events in the relationship between the qi stagnation constitution and depression in women: a moderated mediation model. Evid. Based Compl. Altern. Med. 2017:7605893. doi: 10.1155/2017/7605893

Liu, N., Liu, S., Yu, N., Peng, Y., Wen, Y., Tang, J., et al. (2018). Correlations among psychological resilience, self-efficacy and negative emotion in acute myocardial infarction patients after percutaneous coronary intervention. Front. Psychiatry 9:1. doi: 10.3389/fpsyt.2018.00001

Lopez, R., Calatayud, J., Ezzatvar, Y., José, A., Casajus, and ópez-Sánchez, F. L. (2020). Association between current physical activity and current perceived anxiety and mood in the initial phase of covid-19 confinement. Front. Psychiatry 11:729. doi: $10.3389 /$ fpsyt.2020.00729

Lovibond, P. F., and Lovibond, S. H. (1995). The structure of negative emotional states: comparison of the depression anxiety stress scales (DASS) with the beck depression and anxiety inventories. Behav. Res. Ther. 33, 335-343. doi 10.1016/0005-7967(94)00075-u

Luthans, F., Youssef, C. M., and Avolio, B. J. (2007). Psychological Capital: Developing the Human Competitive Edge. Oxford: Oxford University Press.

Luthar, S. S., and Cicchetti, D. (2000). The construct of resilience: implications for interventions and social policies. Dev. Psychopathol. 12, 857-885. doi: 10.1017/ s0954579400004156

Marques de Miranda, D., da Silva Athanasio, B., Sena Oliveira, A. C., and SimoesE-Silva, A. C. (2020). How is COVID-19 pandemic impacting mental health of 
children and adolescents?. Int. J. Disaster Risk Reduct. 51, doi: 10.1016/j.ijdrr. 2020.101845

Masten, A. S. (2007). Resilience in developing systems: progress and promise as the fourth wave rises. Dev. Psychopathol. 19, 921-930. doi: 10.1017/ s0954579407000442

McFadden, S. H., and Basting, A. D. (2010). Healthy aging persons and their brains: promoting resilience through creative engagement. Clin. Geriatr. Med. 26, 149-161. doi: 10.1016/j.cger.2009.11.00

Miller, N., Perich, T., and Meade, T. (2019). Depression, mania and self-reported creativity in bipolar disorder. Psychiatry Res. 276, 129-133. doi: 10.1016/j. psychres.2019.05.006

Myklebust, J. O. (2000). Children of the great depression. Social change in life experience. Tidsskrift Samfunnsforskning 41, 108-112.

Nijstad, B. A., De Dreu, C. K. W., Rietzschel, E. F., and Baas, M. (2010). The dual pathway to creativity model: creative ideation as a function of flexibility and persistence. Eur. Rev. Soc. Psychol. 21, 34-77. doi: 10.1080/10463281003765323

Nolen-Hoeksema, S. (1991). Responses to depression and their effects on the duration of depressive episodes. J. Abnorm. Psychol. 100, 569-582. doi: 10.1037/ 0021-843x.100.4.569

Nolen-Hoeksema, S., Parker, L. E., and Larson, J. (1994). Ruminative coping with depressed mood following loss. J. Pers. Soc. Psychol. 67, 92-104. doi: 10.1037/ 0022-3514.67.1.92

Ong, A. D., Zautra, A. J., and Reid, M. C. (2010). Psychological resilience predicts decreases in pain catastrophizing through positive emotions. Psychol. Aging 25, 516-523. doi: 10.1037/a0019384

Osofsky, H. J., Osofsky, J. D., and Hansel, T. C. (2011). Deepwater horizon oil spill: mental health effects on residents in heavily affected areas. Disaster Med. Publ. Health Preparedness 5, 280-286. doi: 10.1001/dmp.2011.85

Paek, S. H., Abdulla, A. M., and Cramond, B. (2016). A meta-analysis of the relationship between three common psychopathologies-ADHD, anxiety and depression-and indicators of little-c creativity. Gift. Child Q. 60, 117-133. doi: $10.1177 / 0016986216630600$

Papageorgiou, C., and Wells, A. (2003a). An empirical test of a clinical metacognitive model of rumination and depression. Cogn. Ther. Res. 27, 261273. doi: $10.1023 / \mathrm{a}: 1023962332399$

Papageorgiou, C., and Wells, A. (2003b). Depressive Rumination: Nature, Theory and Treatment. Chichester: John Wiley \& Sons Ltd.

Pietrabissa, G., and Simpson, S. G. (2020). Psychological consequences of social isolation during COVID-19 outbreak. Front. Psychol. 11:2201. doi: 10.3389/ fpsyg.2020.02201

Plass, J. L., and Kalyuga, S. (2019). Four ways of considering emotion in cognitive load theory. Educ. Psychol. Rev. 31, 339-359. doi: 10.1007/s10648-019-09473-5

Plucker, J. A., Beghetto, R. A., and Dow, G. T. (2004). Why isn't creativity more important to educational psychologists? Potentials, pitfalls and future directions in creativity research. Educ. Psychol. 39, 83-96. doi: 10.1207/s15326985ep 3902_1

Plucker, J. A., Runco, M. A., and Lim, W. (2010). Predicting ideational behavior from divergent thinking and discretionary time on task. Creat. Res. J. 18, 55-63. doi: $10.1207 /$ s15326934crj1801_7

Podsakoff, P. M., MacKenzie, S. B., Lee, J.-Y., and Podsakoff, N. P. (2003). Common method biases in behavioral research: a critical review of the literature and recommended remedies. J. Appl. Psychol. 88, 879-903. doi: 10.1037/0021-9010. 88.5.879

Poole, J. C., Dobson, K. S., and Pusch, D. (2017). Childhood adversity and adult depression: the protective role of psychological resilience. Child Abuse Negl. 64, 89-100. doi: 10.1016/j.chiabu.2016.12.012

Post, F. (1996). Verbal creativity, depression and alcoholism - an investigation of one hundred American and British writers. Br. J. Psychiatry 168, 545-555. doi: $10.1192 /$ bjp.168.5.545

Post, F. (2018). Creativity and psychopathology: a study of 291 world-famous men. Br. J. Psychiatry 165, 22-34. doi: 10.1192/bjp.165.1.22

Ran, L., Wang, W., Ai, M., Kong, Y., Chen, J., and Kuang, L. (2020). Psychological resilience, depression, anxiety and somatization symptoms in response to COVID-19: a study of the general population in China at the peak of its epidemic. Soc. Sci. Med. 262:113261. doi: 10.1016/j.socscimed.2020.113261

Richards, R., Kinney, D. K., Lunde, I., Benet, M., and Merzel, A. P. (1988). Creativity in manic-depressives, cyclothymes, their normal relatives and control subjects. J. Abnorm. Psychol. 97, 281-288. doi: 10.1037/0021-843x.97.3.281
Rider Mundey, K., Nicholas, D., Kruczek, T., Tschopp, M., and Bolin, J. (2018). Posttraumatic growth following cancer: the influence of emotional intelligence, management of intrusive rumination and goal disengagement as mediated by deliberate rumination. J. Psychosoc. Oncol. 37, 456-477. doi: 10.1080/07347332. 2018.1514449

Ristevska-Dimitrovska, G., Stefanovski, P., Smichkoska, S., Raleva, M., and Dejanova, B. (2015). Depression and resilience in breast cancer patients. Open Access Maced. J. Med. Sci. 3, 661-665. doi: 10.3889/oamjms.2015.119

Roelofs, J., Huibers, M., Peeters, F., and Arntz, A. (2008). Effects of neuroticism on depression and anxiety: rumination as a possible mediator. Pers. Indiv. Differ. 44, 576-586. doi: 10.1016/j.paid.2007.09.019

Ronald, S., Friedman, Jens Förster, and Markus, D. (2007). Interactive effects of mood and task framing on creative generation. Creat. Res. J. 19, 141-162. doi: 10.1080/10400410701397206

Rubenstein, L. D., Callan, G. L., and Ridgley, L. M. (2017). Anchoring the creative process within a self-regulated learning framework: inspiring assessment methods and future research. Educ. Psychol. Rev. 30, 921-945. doi: 10.1007/ s10648-017-9431-5

Runco, M. A. (2004). Creativity. Annu. Rev. Psychol. 55, 657-687. doi: 10.1146/ annurev.psych.55.090902.141502

Runco, M. A., and Basadur, M. (1990). "Assessing ideational and evaluative skills and creative styles and attitudes," in IEEE International Engineering Management Conference, Gaining the Competitive Advantage (IEEE), (New York, NY: IEEE), 285-289.

Runco, M. A., Plucker, J. A., and Lim, W. (2001). Development and psychometric integrity of a measure of ideational behavior. Creat. Res. J. 13, 393-400. doi: 10.1207/s15326934cri1334_16

Rutter, M. (1999). Resilience concepts and findings: implications for family therapy. J. Fam. Ther. 21, 119-144. doi: 10.1111/1467-6427.00108

Rutter, M. (2006). "Implications of resilience concepts for scientific understanding," in Resilience in Children, eds B. M. Lester, A. S. Masten, and B. McEwen (Oxford: Blackwell), 1-12.

Rutter, M. (2018). Resilience in the face of adversity. Br. J. Psychiatry 147, 598-611. doi: 10.1192/bjp.147.6.598

Sampedro, A., Peña, J., Ibarretxe-Bilbao, N., Sánchez, P., Iriarte-Yoller, N., Pavón, C., et al. (2020). Neurocognitive, social cognitive and clinical predictors of creativity in schizophrenia. J. Psychiatr. Res. 129, 206-213. doi: 10.1016/j. jpsychires.2020.06.019

Schwarz, N. (2000). Emotion, cognition and decision making. Cogn. Emot. 14, 433-440. doi: 10.1080/026999300402745

Sharpley, C. F., Bitsika, V., and Christie, D. R. H. (2011). How prostate cancer patients cope with the effects of diagnosis and treatment: development of the effects of prostate cancer coping strategies scale. J. Men's Health 8, 56-65. doi: 10.1016/j.jomh.2010.12.003

Sharpley, C. F., Bitsika, V., and Christie, D. R. H. (2012). How prostate cancer patients cope: evaluation and refinement of the Prostate Cancer Patients' Coping Strategies Questionnaire. J. Men's Health 9, 70-78. doi: 10.1016/j.jomh. 2012.01.003

Sharpley, C. F., Wootten, A. C., and Christie, D. R. H. (2014). Does resilience "buffer" against depression in prostate cancer patients? A multi-site replication study. Eur. J. Cancer Care 23, 545-552. doi: 10.1111/ecc.12170

Shenesey, J. W., and Langhinrichsen-Rohling, J. (2015). Perceived resilience: examining impacts of the deepwater horizon oil spill one-year post-spill. Psychol. Trauma Theory Res. Pract. Policy 7, 252-258. doi: 10.1037/a003 5182

Shi, L., Sun, J., Wei, D., and Qiu, J. (2019). Recover from the adversity: functional connectivity basis of psychological resilience. Neuropsychologia 122, 20-27. doi: 10.1016/j.neuropsychologia.2018.12.002

Shrout, P. E., and Bolger, N. (2002). Mediation in experimental and nonexperimental studies: new procedures and recommendations. Psychol. Methods 7, 422-445. doi: 10.1037//1082-989x.7.4.422

Silvia, P. J., and Kimbrel, N. A. (2010). A dimensional analysis of creativity and mental illness: do anxiety and depression symptoms predict creative cognition, creative accomplishments and creative self-concepts? Psychol. Aesthet. Creat. Arts 4, 2-10. doi: 10.1037/a0016494

Smith, J. M., and Alloy, L. B. (2009). A roadmap to rumination: a review of the definition, assessment, and conceptualization of this multifaceted construct. Clin. Psychol. Rev. 29, 116-128. doi: 10.1016/j.cpr.2008.10.003 
Solem, S., Hagen, R., Hoksnes, J. J., and Hjemdal, O. (2016). The metacognitive model of depression: an empirical test in a large Norwegian sample. Psychiatry Res. 242, 171-173. doi: 10.1016/j.psychres.2016.05.056

Sternberg, R. J. (2017). Creativity from start to finish: a "straight-A" model of creative process and its relation to intelligence. J. Creat. Behav. 54, 229-241. doi: 10.1002/jocb. 223

Sternberg, R. J. (2018). A triangular theory of creativity. Psychol. Aesthet. Creat. Arts 12, 50-67. doi: 10.1037/aca0000095

Sweetman, D., Luthans, F., Avey, J. B., and Luthans, B. C. (2011). Relationship between positive psychological capital and creative performance. Can. J. Admin. Sci. 28, 4-13. doi: 10.1002/cjas. 175

Taheri-Kharameh, Z., and Hazavehei, M. M. (2017). Anxiety, depression and resilience in elders with chronic diseases. Eur. J. Publ. Health 27(Suppl._3), 484. doi: 10.1093/eurpub/ckx186.236

Takács, J. (2014). Regular physical activity and mental health. the role of exercise in the prevention of, and intervention in depressive disorders. Psychiatr. Hungar. 29, 386-397. doi: 10.1016/j.ijleo.2013.07.170

Tan, L., Liu, K., Yan, X., Liu, L., Lu, T., Chen, J., et al. (2018). Robust visual secret sharing scheme applying to QR code. Sec. Commun. Netw. 2018, 1-12. doi: 10.1155/2018/4036815

Teismann, T., Het, S., Grillenberger, M., Willutzki, U., and Wolf, O. T. (2014). Writing about life goals: effects on rumination, mood and the cortisol awakening response. J. Health Psychol. 19, 1410-1419. doi: 10.1177/ 1359105313490774

Treynor, W., Gonzalez, R., and Nolen-Hoeksema, S. (2003). Rumination reconsidered: a psychometric analysis. Cogn. Ther. Res. 27, 247-259. doi: 10. 1023/a:1023910315561

Tsai, K. C. (2015). Assessing a Chinese version of the runco ideational behavior scale. Soc. Behav. Pers. 43, 1111-1122. doi: 10.2224/sbp.2015.43.7.1111

Tugade, M. M., and Fredrickson, B. L. (2004). Resilient individuals use positive emotions to bounce back from negative emotional experiences. J. Pers. Soc. Psychol. 86, 320-333. doi: 10.1037/0022-3514.86.2.320

Vahle-Hinz, T., Mauno, S., Bloom, J., and Kinnunen, U. (2017). Rumination for innovation? Analysing the longitudinal effects of work-related rumination on creativity at work and off-job recovery. Work Stress 31, 315-337. doi: 10.1080/ 02678373.2017.1303761

van der Werff, S. J. A., van den Berg, S. M., Pannekoek, J. N., Elzinga, B. M., and van der Wee, N. J. A. (2013). Neuroimaging resilience to stress: a review. Front. Behav. Neurosci. 7:39. doi: 10.3389/fnbeh.2013.00039

Varshney, L. R., Pinel, F., Varshney, K. R., Schorgendorfer, A., and Chee, Y. M. (2013). "Cognition as a part of computational creativity," in Proceedings of the 2013 IEEE 12th International Conference on Cognitive Informatics and Cognitive Computing (IEEE), (New York, NY: IEEE), 36-43.

Verhaeghen, P., Joorman, J., and Khan, R. (2005). Why we sing the blues: the relation between self-reflective rumination, mood and creativity. Emotion 5, 226-232. doi: 10.1037/1528-3542.5.2.226

Wallas, G. (1926). The Art of Thought. New York, NY: Harcourt Brace.
Wang, Y., Jing, X., Han, W., Jing, Y., and Xu, L. (2020). Positive and negative affect of university and college students during COVID-19 outbreak: a network-based survey. Int. J. Publ. Health 65, 1437-1443. doi: 10.1007/s00038-020-01483-3

Watkins, E. R. (2008). Constructive and unconstructive repetitive thought. Psychol. Bull. 134, 163-206. doi: 10.1037/0033-2909.134.2.163

Wojujutari, A. K., Alabi, O. T., and Emmanuel, I. E. (2019). Psychological resilience moderates influence of depression on sleep dysfunction of people living with diabetes. J. Diabetes Metab. Disord. 18, 429-436. doi: 10.1007/s40200-01900436-9

$\mathrm{Wu}, \mathrm{X}$., Zhou, X., Wu, Y., and An, Y. (2015). The role of rumination in posttraumatic stress disorder and posttraumatic growth among adolescents after the Wenchuan earthquake. Front. Psychol. 6:1335. doi: 10.3389/fpsyg.2015. 01335

Wu, Y., Zhao, X., Ding, X., Yang, H., Qian, Z., Feng, F., et al. (2015). A prospective study of psychological resilience and depression among left-behind children in China. J. Health Psychol. 22, 627-636. doi: 10.1177/1359105315610811

Xiang, Y., Chao, X., and Ye, Y. (2018). Effect of gratitude on benign and malicious envy: the mediating role of social support. Front. Psychiatry 9:139. doi: 10.3389/ fpsyt.2018.00139

Xiang, Y., Dong, X., and Zhao, J. (2020). Effects of envy on depression: the mediating roles of psychological resilience and social support. Psychiatry Invest. 17, 547-555. doi: 10.30773/pi.2019.0266

Xurui, T., Yu, Y., Li, Q., Mao, Y., Zhou, B., and Bao, X. (2018). Mechanisms of creativity differences between art and non-art majors: a voxel-based morphometry study. Front. Psychol. 9:2319. doi: 10.3389/fpsyg.2018.02319

Zhang, Y., Xu, W., Yuan, G., and An, Y. (2018). The relationship between posttraumatic cognitive change, posttraumatic stress disorder and posttraumatic growth among Chinese adolescents after the Yancheng tornado: the mediating effect of rumination. Front. Psychol. 9:2319. doi: $10.3389 /$ fpsyg.2018.00474

Zhou, T., Nguyen, T. T., Zhong, J., and Junsheng Liu, J. (2020). A COVID-19 descriptive study of life after lockdown in Wuhan, China. R. Soc. Open Sci. 7:200705. doi: 10.1098/rsos.200705

Zhu, W., Shang, S., Jiang, W., Pei, M., and Su, Y. (2019). Convergent thinking moderates the relationship between divergent thinking and scientific creativity. Creat. Res. J. 31, 320-328. doi: 10.1080/10400419.2019.1641685

Conflict of Interest: The authors declare that the research was conducted in the absence of any commercial or financial relationships that could be construed as a potential conflict of interest.

Copyright (c) $2021 \mathrm{Xu}$, Shao, Zeng, Wu, Huang, Zeng and Wu. This is an open-access article distributed under the terms of the Creative Commons Attribution License (CC BY). The use, distribution or reproduction in other forums is permitted, provided the original author(s) and the copyright owner(s) are credited and that the original publication in this journal is cited, in accordance with accepted academic practice. No use, distribution or reproduction is permitted which does not comply with these terms. 